\title{
A Multimodal Analysis of Students' Commercial Copywriting
}

\author{
Riesky \\ English Language and Literature Study Program \\ Universitas Pendidikan Indonesia \\ Bandung, Indonesia
}

\begin{abstract}
Meanings in nowadays digitally based communication have been increasingly exchanged in a more multimodal form. Messages, which were once dominantly conveyed in verbal texts, have transformed into a variety of appearances that include the combination of different modes, such as texts, sounds, images and videos. This is also applied when people want to influence others for commercial purposes. This study is aimed at unpacking the ways commercial copies are constructed from the perspective of multimodality. From 49 commercial copies created by university students, 10 best copies according to peer evaluation were further analyzed. Three important aspects are focused on, namely the elements of copy, the meanings of composition, and the relationship between images and text, by respectively following the theoretical frameworks proposed by Maslen (2009), Kress and van Leeuwen (2006), and Marsh and White (2003). The study results in three important findings. First, benefit becomes the most dominant element in the copies. Second, in terms composition, the most dominant position of information value is top and bottom, emphasizing more on the relation of ideal and real. Salience is emphasized equally on both the textual and the visual elements, and so is the degree of connection and disconnection of visual elements. Finally, in terms of relationship between images and texts in the copies, functions of images expressing close relationship to the texts are mostly built. Students' awareness to provide relevant images for the texts in their copies are evidenced in this study.
\end{abstract}

Keywords-mode; multimodal; copywriting; commercial; composition.

\section{INTRODUCTION}

The ability to influence people through texts has become an important skill nowadays. Creating a text that can persuade others is now part of the curriculum of English in the secondary schools and many universities in Indonesia. Producing texts that are persuasive in nature has in fact important in many fields of human life, including education, business, and social relationship. Many agreements, collaborations, and public projects become successful when the parties involved can influence each other in a more positive and beneficial way.

With the rapid development of Information and Communication Technology (ICT), the characteristics of persuasive texts have changed into a more multimodal form. Persuading others that once used to be done by relying mostly on verbal texts has now appeared in a combination of texts, sound, images, and even videos. People communicate in a more complex way using more varieties of semiotic modes with each other. The way meanings are shared and negotiated then becomes more dynamic and more complicated. The availability of many multimodal features in people's gadgets has influenced people's habits in creating messages, including how they give responses to every message they receive. The business of influencing others through a variety of multimodal messages has now become more and more dominant and influential.

Multimodality is simply about the creation of meaning through different components, which are called modes. Multimodality refers to a term used to talk about how meaning is constructed through a combination of different semiotic modes for the purpose of communication (see van Leeuwen, 2005; Baldry \& Thibault, 2006; Jewitt, 2013). The term mode itself is defined as a resource for making meaning, which is culturally bound (Kress, et. al., 2005). With the appearances of various multimodal texts in a digitalized world nowadays, the ways people understand meanings in their daily communication have also shifted, requiring them not only to understand the texts but also the other accompanying modes.

Multimodal texts have become increasingly apparent in many aspects of human socioeconomic lives particularly in the last decade. Triggered by the appearance of high-tech gadgets that provide a wide range of multimodal features, the way people interact and communicate have dramatically changed. In social life, social connections are now built through the use of different platforms of social media, such as Facebook, Instagram, Twitter, etc. People connect and know each other by sharing texts, photos and even videos. Personal and community lives are now documented well in multimodal forms in the internet. Economy has also shifted in many ways. Trades are now utilizing many forms of modes. The way people market and sell their products is an obvious example that can be seen every day. Products are no longer described dominantly through texts, but with the combination of texts, pictures, and videos, increasing the attractiveness of products in the eyes of potential consumers.

This study investigated how multimodality is reflected in the copies created by the students following a copywriting course in a university in West Java. The focus of the study is on three important aspects namely the elements of copy, the meanings of composition, and the relationship between images and texts. By focusing on those three aspects, this study attempted to unpack how persuasive texts, in the forms of commercial copies created by university students, can be understood from a more multimodal approach to copywriting. 


\section{LITERATURE REVIEW}

\section{A. Copywriting in the Digital Era}

Copywriting is about how to sell something by writing. Judith Charles (as cited in Bly, 2005) states that a copywriter is "a salesperson behind a typewriter." This suggests that at the end what matters most for copywriters is not about how to create a copy that is interesting to see or to read but to create a copy that sells. The focus on writing a copy is essentially not on entertaining or winning an award, but on increasing sales and gaining profit.

Since the main focus is on selling, influencing the readers becomes an important key here. A good copywriter, according to Maslen (2009), will prioritize understanding the readers than other things. It is not about the products sold, the company, or current special offers and promotions. At the end, it is about what the readers, who can be the potential customers, think, feel and want in relation to the products offered.

The practice of copywriting has changed from time to time. Entering the nowadays digital era, the practices of copywriting also have to adapt to the conditions and the behaviors of the consumers. With the emergence of smartphones that enable e-commerce and even m-commerce (mobile commerce), the content of the copy created should be made more "informative, clear, and compelling" (see Shaw, 2012). Copywriting in the digital era requires copywriters to create a brief and to-the-point copy that highlights the benefits that the consumers can get from the products or services. This is due to the fact that smartphone users tend to scan not to read what appears on the screen. That is why being simple and interesting becomes important.

\section{B. The Meaning of Composition in Multimodal Texts}

When multimodal texts, including commercial copies that become the focus in this study, are constructed, the interaction among various semiotic modes creates patterns of relations and integrates into a meaningful whole (see Kress \& van Leeuwen, 2006). The placement of each element in a multimodal text is meaningful. That is why composition becomes an important aspect that contributes to how meaning is negotiated in a multimodal text.

The meaning of composition as suggested by Kress and van Leeuwen (2006) is heavily influenced by the concept of textual meaning in Systemic Functional Linguistics proposed by Halliday (1994). Simply speaking, it is the adaptation of textual meaning into the study of multimodal texts, on how elements of multimodal texts are arranged and placed. In the analysis of meaning, three important aspects are further examined, namely (1) information value, (2) salience, and (3) framing.

Information value is about how elements in a multimodal text are positioned and therefore influence the meanings that emerge. The categories of position arrangement include left and right, top and bottom, and center and margin.

Left and right is related to the information status of "Given and New". When information is positioned on the left, it is usually something "Given" or "already known. Meanwhile, if it is presented on the right, the information is regarded "New" or "key". Top and bottom is often associated with the "Ideal and Real" values. Information at the top is considered "Ideal", which often becomes the most important part, the gist, or the generic idea of the information. Information placed at the bottom, on the other hand, represents the "Real", functioning as the more detail, specific, or practical one. Center and margin is related to the arrangement of positions in the middle and the surrounding area. The element put in the center is considered the main or the central part, while other elements surrounding it represent the "Margin" or the subordinate ones.

Salience in composition is related to the degree of importance, or worthiness, or attractiveness. There are many ways salience is realized in a multimodal text. Technically speaking, it can be realized by the use of colors, size, shapes, types of fonts, etc. The variations of creating salience is directed towards how to create a contrast, to make certain elements weigh more than others.

The third aspect in composition is framing. It has to do with how to create a sense of connection and separation among the elements in a multimodal text. Colors and lines, for example, can become a tool to create a separator among elements. The more separations are created, emphasis on individual identity or differentiation becomes stronger.

\section{How Images and Texys are Related in Multimodal Texts}

With the rapid emergence of multimodal texts, studies on the variety of multimodal constructions and how to unpack the meanings of them become more intensively conducted. Researchers start to conduct studies to learn how a variety of semiotic modes, e.g. texts and images, interact and create meanings. Rooted in the tradition of Systemic Functional Linguistics (SFL), some studies started to explore this phenomenon. What has happened is that the framework of SFL that was used to conceptualize language as an interrelated system is now widely adopted for the "descriptions of the meaning-making resources of other semiotic modes" (Unsworth, 2006, p. 58). Some studies on semiotic modes that started to emerge in this case, to take an example, were those by Kress and van Leeuwen (1996), O'Toole (1994), and Lemke (1998).

In the present study, however, the framework used to analyze the relationships between images and texts is based on what has been proposed by Marsh and White (2003). They established a taxonomy of image-text relationships that reflects the ways that images and texts interact. Simply put, the taxonomy classifies the relationships into three main categorical functions based on the closeness of conceptual relationship between image and text, namely (A) function expressing little relation to the text, (B) function expression close relation to the text, and $(\mathrm{C})$ function that go beyond the text. The taxonomy is simply depicted in the table below. 
TABLE I. A SIMPLIFIED VERSION OF TAXONOMY OF FUNCTIONS OF IMAGES TO THE TEXT (ADAPTED FROM MARSH \& WHITE, 2003)

\begin{tabular}{|l|l|l|}
\hline $\begin{array}{c}\text { (A) Functions } \\
\text { Expressing Little } \\
\text { Relation to The Text }\end{array}$ & $\begin{array}{c}\text { (B) Functions } \\
\text { Expressing Close } \\
\text { Relation to The Text }\end{array}$ & $\begin{array}{c}\text { (C) Functions That } \\
\text { Go beyond The Text }\end{array}$ \\
\hline A1 Decorate & B1 Reiterate & C1 Interpret \\
\hline A2 Elicit Emotion & B2 Organize & C2 Develop \\
\hline A3 Control & B3 Relate & C3 Transform \\
\hline & B4 Condense & \\
\hline & B5 Explain & \\
\hline
\end{tabular}

\section{METHOD}

The study involved 49 commercial copies created by students taking Copywriting course in a university in West Java. From those 49 copies submitted, only 10 copies that were further analyzed. The sorting out of the ten out of the forty-nine copies was conducted by asking 26 junior student respondents to rate the copies by considering five aspects, namely (1) clarity of intention, (2) degree of being interesting, (3) text quality, (4) visual quality, and (5) overall design. Each respondent was asked to rate all the copies by giving a score ranging 1-5. After the ten best copies were selected, the analysis was then conducted by applying three important theoretical frameworks proposed by Maslen (2009), Kress and van Leeuwen (2006), and Marsh and White (2003) respectively to see how the elements of copy are distributed, the meanings of composition are constructed, and the relationship between images and text are built.

\section{RESULT AND DISCUSSION}

\section{A. The Distribution of Copy Elements}

Copy elements analyzed in this study refer to three elements that generally appear in a copy, which consist of feature, benefit, and call to action (see Maslen, 2009). From 10 copies that advertise 8 products and 2 services, 9 out of 10 contain call to action; 8 out of 10 contain benefit; 7 out of 10 contain feature, as depicted in Figure 1.

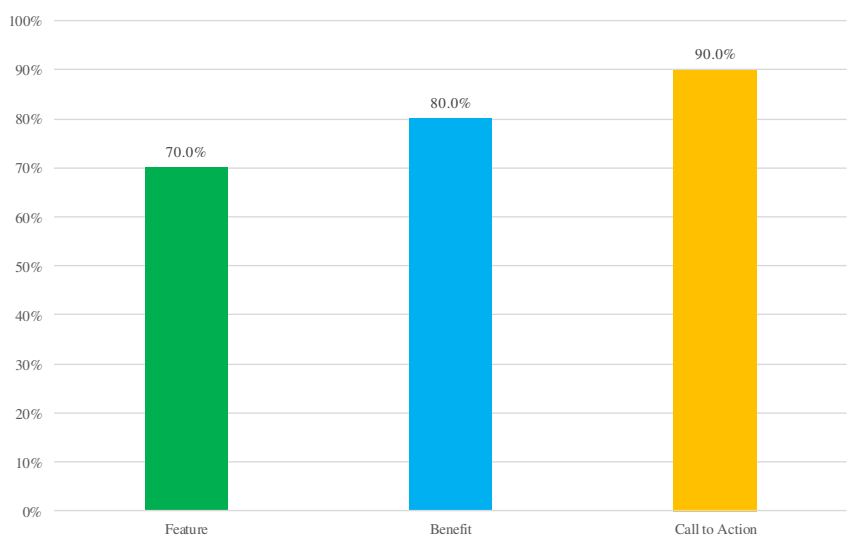

Fig. 1. The Distribution of Copy Elements

From the figure above, it seems obvious that almost all the copywriters (the students taking a Copywriting course) use call to action in their copy. Since a copy is mainly intended to make the readers (potential customers) do something as directed by the message in the copy, call to action simply asks the readers to do something, that is, to buy the products or services offered. Call to action is simply about to trigger the expected action, what the copywriter wants most from the readers or the customers. It is the heart of selling, of gaining profit in business.

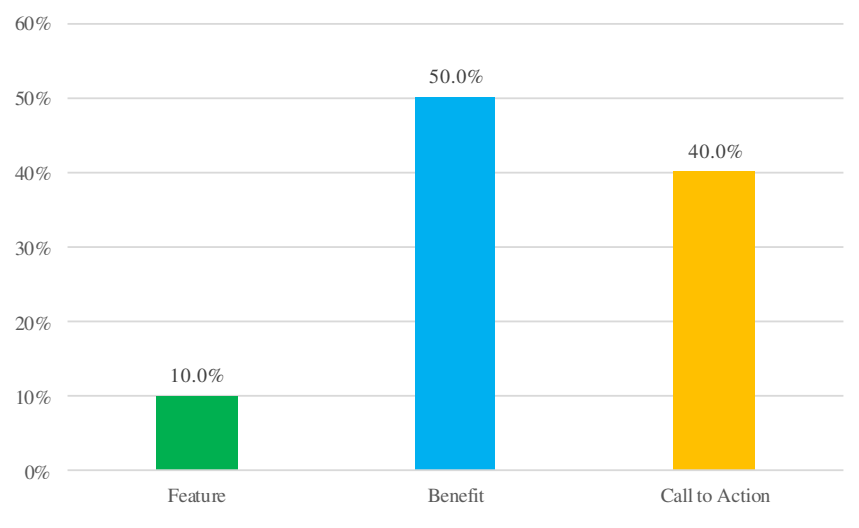

Fig. 2. Copy Elements Emphasized

However, when it is analyzed based on which element is emphasized in the copy, benefit is the most dominant one. 5 out of 10 copies emphasize benefit as the dominant part in the copy; 4 out of 10 copies emphasize call to action; only 1 copy emphasizes feature in this case. Emphasis in this analysis means the biggest portion occupied by a copy element.

Why does benefit have such a strong emphasis in most of the students' commercial copies? This finding is not particularly surprising. Benefit in copies, as underlined by Shaw (2012), is used to address the "so what?" factor in the head of potential customers. Customers may ask "so what?" to every statement or claim the copywriter creates. By explicitly putting forward the benefits that the reader can easily spot in the copy, copywriters position the readers as the main concern in their copies. This is because, as Maslen (2009) emphasized, the single most important thing in copywriting is actually the readers, as potential customers.

Overall, the analysis on copy elements shows that benefit and call to action tend to dominate the elements present in the copies. Even though feature is present in the copy, it does not become the main element to emphasize. The main consideration that creating a copy is mostly about selling and focusing on the readers seems to result in the dominant use of benefit and call to action in the students' copies.

\section{B. The Meanings of Composition in The Copies}

The meaning of composition in this study is based on the concept proposed by Kress and van Leeuwen (2006), which comprises three important components, namely (1) information value, (2) salience, and (3) framing. Based on the results of analysis, some important findings are depicted in Figures 3 to 5 . 
As obviously seen from Figure 3 below, top and bottom placement of information dominates how the information value is arranged in the copies. The information value of top and bottom, as suggested by Kress and van Leeuwen (2006), can indicate two important possibilities of meaning relationship, namely "ideal and real" and "general and specific".

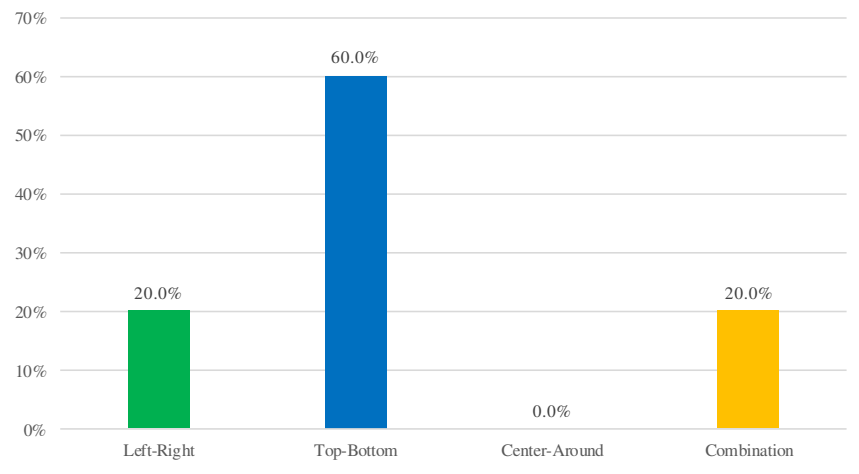

Fig. 3. Information Values

As analyzed from the six copies that use top and bottom placement of information, most of the copies construct a more "general and specific" relationship. The "general" information, which is placed at the top, is mostly realized in the form of the name or brand of the product or the service offered. Some of the information placed at the top also contains call to action, which also becomes the most frequent element appearing in the copies. Meanwhile, the "specific" information, which is placed at the bottom of the copy, tends to be more technically informative. It is the part where more detailed information is provided. The bottom information, in this case, is dominated by benefit. Most copies position information about benefit at the bottom as a part that needs more specific and detailed elaboration. This becomes understandable because the clearer the benefit is explained, the higher the chance of influencing readers to buy a product or a service.

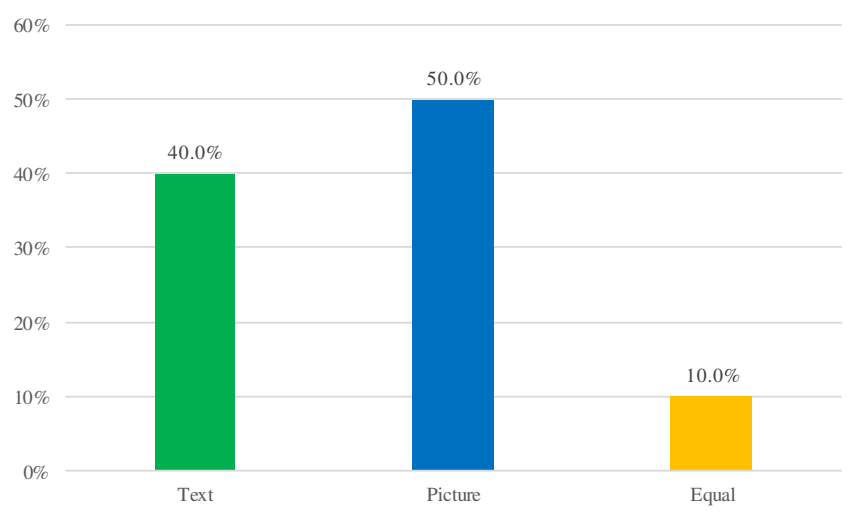

Fig. 4. Salience

In terms of salience, as depicted in the figure above, the most frequent emphasis in given on the visual mode (picture). There are 5 out of 10 copies that foreground the picture than the text. Text is also made salient in 4 out of 10 copies, not far behind the visual mode. Reflecting on salience, it is evidenced that the use of visual mode in the recent years becomes more dominant in people's socioeconomic life. To some extent, it is understandable due to at least two important reasons. First, the rapid advancement of ICT has also impacted to the mass production of high-tech audiovisual gadgets, such as cellphones. Cellphones nowadays are not only functioned as a tool for texting and calling but also used as a recording device for photo and video. The ease of taking pictures and sharing them with others has made the visual production and interaction more intense among people. Second, from the psychological perspective, the use of pictures or other visual forms helps readers remember the message longer. Medina (2008) underlined that visual inputs are recognized and recalled more easily than textual ones. Therefore, people will be very likely to remember visual information longer than oral or textual information. People can only remember $10 \%$ of the oral information in comparison to $65 \%$ of a combination of oral and visual information after 72 hours the information is given to them. This phenomenon is then popularly known as the Pictorial Superiority Effect or simply called PSE.

The interesting thing about creating salience is also about the technique used and what element is focused on. In relation to the technique, besides the positioning of the element and the use of colors, salience in both text and picture is mostly created by making them bigger. Most copies analyzed play with size to create contrast. When it is analyzed in relation to the kind of copy element, two important patterns emerge. When the salience is given on the text, it is mostly about benefit and label of the brand. While when it is on the picture, it is dominantly about the products offered.

As for the analysis of framing, the way the textual and visual modes are combined in the copies are significantly different. Seven out of ten copies are made with clear frames or dividing lines that indicate the attempt to separate the elements in the copies. The remaining three copies do not create a separating line and seem to create a sense of unity among the elements.

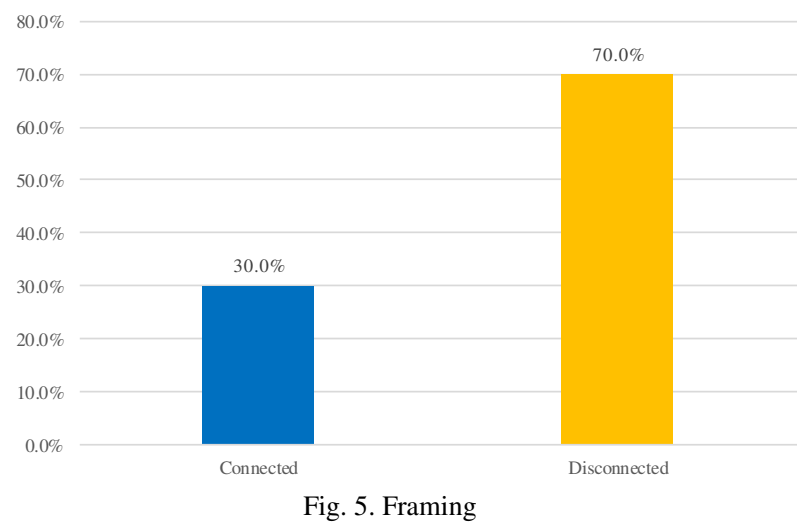

What is found here indicates that most student copywriters tend to separate the elements in their copies. This can simply be a matter of style or choice. A possible explanation for this is that the copywriters just want to create a clear boundary among the copy elements in their copywriting. By making each element of the copy clear and distinct one another, there 
is an expectation that readers can easily understand different types of messages presented in the copies.

\section{The Relationships between Images and Texts}

As suggested by Marsh and White (2003), documents in the recent time become more complex to analyze. The elements involved are often a combination of several different semiotic modes such as texts and images. The results of the analysis on the relationship between images and texts are depicted in the figure below.

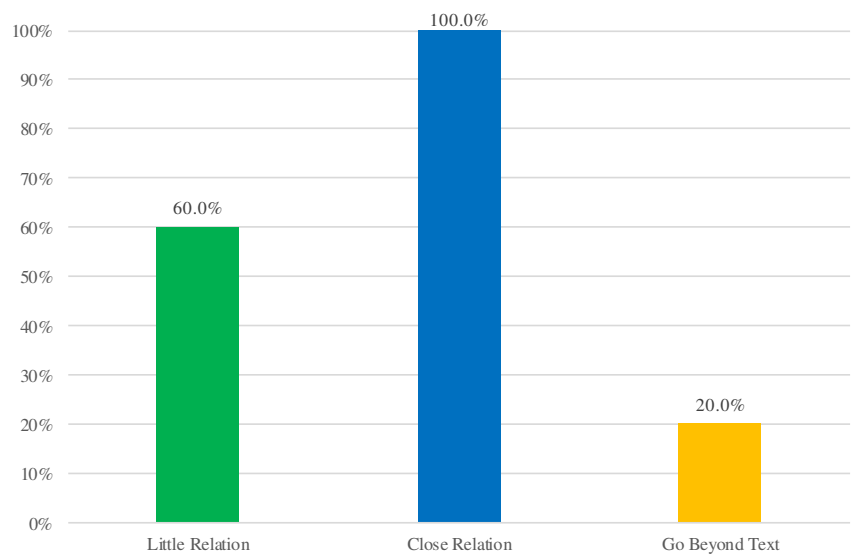

Fig. 6. Image and Text Relation

Since one document can have more than one relationship between the image and the text, several important patterns can be identified from the graph above. All the images used basically have close relation to the text they write in their copies. All of the student copywriters seem to already have a good sense of creating a conceptually related combination of texts and images in their copies. Based on the analysis, most of the close relations built between the images and the texts are to reiterate, more specifically to concretize and to exemplify the concepts or information provided in the text.

However, some additional functions are also present in the copies. In 6 out of 10 copies, functions expressing little relation are also evidenced, which are mainly to control with the focus of motivating the readers to buy the products or services. There are also 2 copies that have function that goes beyond the text, which is to transform or more specifically to physically model the information provided by the texts. Overall, in terms of relationships between texts and images, the multimodal copies created by the students have been constructed in a way that strengthen the closeness of conceptual interaction. As a generation raised in the digital and a more multimodal era, the student copywriters have convincingly demonstrated a good visual literacy.

\section{CONCLUSION}

A multimodal approach that was applied in analyzing students' commercial copies has shown that the ways meanings are constructed have become more complex and potentially result in different interpretations from the perspectives of the readers. However, by focusing on some specific aspects and by using a specific tool and a systematic framework, researchers can gain meaningful insights on how various elements in a multimodal text interact, create unique patterns, and logically connect to create a specific intentional meaning.

\section{References}

Baldry, A. \& Thibault, P.J. (2006). Multimodal transcription and text analysis. London: Equinox.

Bly, R. W. (2005). The copywriter's handbook: A step-by-step guide to writing copy that sells ( $3^{\text {rd }}$ ed.). New York: Henry Holt and Company.

Halliday, M.A.K. (1994). An introduction to functional grammar $\left(2^{\text {nd }}\right.$ ed.). London: Edward Arnold.

Jewitt, C. (2013). Learning and communication in digital multimodal landscapes: An inaugural professorial lecture by Carey Jewitt. London: Institute of Education Press.

Kress, G. \& van Leeuwen, T. (1996). Reading images: A grammar of visual design. London: Routledge.

Kress, G. \& van Leeuwen, T. (2006). Reading images: The grammar of visual design ( $2^{\text {nd }}$ ed.). Oxon: Routledge.

Kress, G., Jewitt, C., Bourne, J., Franks, A., Hardcastle, J., Jones, K., \& Reid, E. (2005). English in urban classrooms: A multimodal perspective on teaching and learning. Oxon: Routledge Falmer.

Lemke, J. (1998). Multiplying meaning: Visual and verbal semiotics in scientific text. In J.R. Martin \& R. Veel (Eds.), Reading science: Critical and functional perspectives on discourses of science (pp. 87-113). London: Routledge.

Marsh, E.E. \& White, M.D. (2003). A taxonomy of relationship between images and text. Journal of Documentation, 59, 647-672. doi: 10.1108/00220410310506303.

Maslen, A. (2009). Write to sell: The ultimate guide to great copywriting. London: Marshall Cavendish Ltd.

Medina, J. (2008). Brain rules: 12 principles for surviving and thriving at work, home and school. Seattle: Pear Press.

O'Toole, M. (1994). The language of displayed art. London: Leicester University Press.

Shaw, M. (2012). Copywriting: Successful writing for design, advertising, and marketing $\left(2^{\text {nd }}\right.$ ed.). London: Lauren King Publishing.

Unsworth, L. (2006). Towards a metalanguage for multiliteracies: Describing the meaning-making resources of language-image interaction. English Teaching: Practice and Critique, 5(1), 55-76.

van Leeuwen, T. (2005). Introducing social semiotics. London: Rouledge. 